\title{
An Exploratory Study of Value Added Services
}

\section{Hossein GT Olya, Levent Altinay, Glauco De Vita}

Paper accepted by Journal of Services Marketing, on $21^{\text {st }}$ November 2017.

DOI: 10.1108/JSM-12-2016-0415

\begin{abstract}
Purpose: Using data from 104 countries over a six-year period (2009-2014), this study proposes a value-added predictor in service industries based on the eight indicators of the prosperity index, namely economy, entrepreneurship and opportunity, governance, education, health, safety and security, personal freedom, and social capital.

Design/methodology/approach: The fuzzy-set qualitative comparative analysis (fsQCA) and complexity theory, a relatively novel approach for developing and testing the conceptual model, are used for asymmetric modelling of value added in service industries, and the predictive validity of the proposed configural model is tested.
\end{abstract}

Findings: Apart from advancing method and theory, this study simulates causal conditions (i.e., recipes) leading to both high and low scores of the value added of services. The configural conditions indicating a high/low level of value added in service industries can be used as a guiding strategy for marketers, investors and policy makers.

Originality/value: An analysis of worldwide data provides complex models demonstrating both how to regulate country conditions to achieve a high value-added score and select a foreign country for investment that offers a high level of value added service.

Keywords: Value added; complexity theory; fsQCA; asymmetric modelling; service 


\section{Introduction}

Value-added product and service development, defined as the creation of an array of sequential activities to bring more custom-tailored services to the marketplace (Hilton, Hughes and Chalcraft 2012; Ostrom et al., 2010), has been investigated by various disciplines including economics, organisational studies and marketing, with studies being informed by different theoretical perspectives ranging from the resource-based view to institutionalisation theory. Value added has also been investigated across many sectors such as tourism (e.g., Lexhagen 2004), banking (e.g., Echchakoui 2016), transportation (e.g., Martínez-Torres et al., 2013), education (e.g., Cunha and Miller 2014), telecommunication (e.g., Daim et al., 2014; Kuo et al., 2009), and energy (e.g., Randers 2012).

Value-added products and services help organisations compete and survive in a turbulent business environment (Echchakoui 2016; Jiao et al., 2003; Ryan 1996) and, from a marketing strategy perspective, positively affect customer behaviour (Grönroos 1997; Lexhagen 2004). More specifically, they can generate various benefits such as increased sales revenue, reduced financial risk and enhanced market diversification. In a study of tour operators and travel agencies, Lexhagen (2004) reports that value-added services provided by websites for tour operators and travel agencies significantly affect customers' search and purchase processes. Liu and Leach (2001) state that organisational buyers consider valueadded services offered by suppliers as a ploy for establishing a long-run business relationship, while Grönroos (1997) highlights how value added represents the utilitarian value for the customer. In this regard, Echchakoui (2016) finds that experiential value added mediates the relationship of intangible resources of supply side and positive behavioural intentions of customers (e.g., loyalty and share of wallet).

Collectively, these and other related studies have made a significant contribution to the services management literature by evidencing the importance of value added in the service industries. Nevertheless, we still know very little about the key drivers and causal, 
complex macro-environmental conditions that can be seen as enablers for value added service (Wirtz et al., 2015). Similarly, Gustafsson et al. $(2016,14)$ observe that "multidisciplinary borrowed theories and concepts often remain largely unmodified when used to study phenomena, such as value." The present study intends to fill this gap, and hence advance the debate, by providing a universal model regarding causal conditions for simulating value added services at a macro level; an important endeavour that appears to have been overlooked in previous research. Understanding the complexities of service value added from a macro socio-economic perspective appears to us to be particularly important and opportune because although value added services contribute to the competitiveness of a country, there is a dearth of studies investigating the main contributors of service value added at macro country level (Ahmet Erkoyuncu et al., 2014; Martínez-Torres et al., 2013; Van Vliet 2014).

We pursue this aim, first, by developing a configural model for simulation of value added in service industries based on eight indicators of prosperity - economy, entrepreneurship and opportunity, governance, education, health, safety and security, personal freedom, and social capital - which are computed and issued by the Legatum Institute (2016). This index has been estimated using an econometric analysis comprising 89 variables, which are spread across the aforementioned eight sub-indices (Legatum 2013). Value added in services is selected as an outcome condition, based on the International Standard Industrial Classification (ISIC) divisions 50-99. Following the World Bank (2016) classification, services include "wholesale and retail trade (including hotels and restaurants), transport, and government, financial, professional, and personal services, such as education, health care and real estate services." 1 Elango and Wieland $(2015,588)$ stated that "understanding the impact of country effect on financial performance is important for service firms as they continue to grow and operate across national borders."

This study contributes to existing knowledge of service marketing strategy by developing a configural model for simulating value added of services by a combination of 
eight indicators of a composite prosperity index that explains the socio-economic conditions of countries. Although many studies assessed the outcomes of value added at the micro level, it is striking that no study has explored possible complex configurations of antecedent conditions of this concept on a wider, national scale. In addition, as Chandra et al. (2001) recognised, value added service is a complex issue, and the complex interactions of eight subindices of prosperity can function as indicators of value added services of a country. On the basis of this premise, we seek to present a more holistic insight that by considering eight socio-economic factors in a configural model, describes consistent and sufficient conditions for achieving value added services. Moreover, besides proposing a new conceptual model of antecedents of value added of services, the model is tested using a novel analytical approach, which combines fuzzy-set qualitative comparative analysis (fsQCA) with complexity theory. This approach helps to explain the complex interactions of antecedent conditions (in our case the eight indicators of prosperity) and outcome condition (the value added services) in predicting socio-economic phenomena (Woodside 2015; Wu et al., 2014). Moreover, we assess the predictive validity of the model (Gigerenzer and Brighton 2009). Wu et al. (2014) recently noted that "unfortunately, only a handful of studies report on predictive validity, nearly all studies report only on fit validity."

This study provides both theoretical and methodological contributions to the current knowledge of value added services. First, this is the first study that employs eight indices of prosperity for predicting value added services at a macro level by using data from 104 countries over a six-year period (2009-2014). Although relevant literature supports the associations of the separate indicators (not all eight factors together, with value added as outcome of the model), this study is the first to use a combination of all eight factors as a causal complex configuration to predict the outcome. Second, previous studies called for the application of new theory and methods for modeling value added in service industries. The present study answers precisely these calls by being the first in 
applying asymmetrical modelling (i.e., fsQCA) in conjunction with complexity theory to explore causal algorithms leading to both high and low value added services. To the best of our knowledge, previous research investigated the model indicating high value added services and simply considered mirror opposite of the causal model for low scores of value added services. Our findings advance knowledge in this field by showing that value added services at a macro scale are a complex phenomenon and causal models for high value added are not a mirror opposite of models predicting low value added. Therefore, application of asymmetrical modelling to explore complex combinations of the factors for predicting both a high and low score of the outcome (i.e., value added) constitutes a valuable additional tool for knowledge generation (Kan et al., 2016). By identifying and evaluating the key drivers and causal complex macro-environmental conditions that enable value added services, the results of this study are informative as to what complex interactions of eight sub-indices of prosperity (i.e., causal model) could be attuned to explain conditions of high and low scores of value added services at a macro scale. The paper demonstrates that economy, entrepreneurship and opportunity, governance, education, health, safety and security, personal freedom, and social capital, interact with and influence each other thereby contributing to the value added services of countries.

\subsection{Conceptualization}

Including and extending services in a product portfolio adds 'value' from the customer's perspective (Hilton et al., 2012; Ostrom, Parasuraman, Bowen, Patrício, and Voss 2015). Value-added services, in particular, extend organisations' ability to compete beyond the traditional measures of the product driven-focussed approach to manufacturing, to competitiveness such as cost, quality, flexibility, and delivery (Youngdahl and Loomba 2000). Value added services are crucial for the differentiation, competitiveness and 
performance of organisations in today's business environment, which is more turbulent than ever before (Ostrom et al., 2010; Stacey et al., 2000). Country conditions - in terms of “institutional norms and cultural values, the national government's economic and industrial policies, and economic and physical resources and industrial capabilities" (Elango and Wieland 2015, 591) — affect competitive success of business services that plays key role in adding value to the output of manufacturing as well as trade value (ibid, 591). In internationalisation and international service management, additional value captures from the ability to shift work from one location to another to take advantage of shifts in the factors of production (Huber and Danino 2012). Gustafsson et al. (2016) called for developing models in service research supported by a theory that explain complex interactions of a wide ranges of indicators (i.e. from economic to social issue) as follows:

The research should apply original service research and other scientific theories, and models to address the interactive, contextual, systemic, experiential, and relational nature of service. Essentially, to provide an important transdisciplinary foundation that link and transcends demand-side and supply-side views on value creation that can advance the understanding of, e.g., service innovation, competition, and individual, organizational, and societal growth and well-being (Gustafsson et al., 2016, 10).

Prosperity has two pillars: economic and emotional facets; the latter defined as well-being measured in human terms (Madonia et al., 2013; Oswald 2010). Edvardsson et al. (2011, 327) argue that "value should be understood as value-in-social-context and that value is a social construction. Value co-creation is shaped by social forces, is reproduced in social structures, and can be asymmetric for the actors involved." Considering these arguments, this study explores the complex patterns of prosperity antecedents in simulating value added in services. Corley and Gioia noted that "theory is a statement of concepts and their interrelationships that shows how and/or why a phenomenon occurs" $(2011,12)$. Using complexity theory and fsQCA, this exploratory research advances the theory and method by 
asymmetrical modelling of value added in services based on interactions of socio-economic antecedents of prosperity. In other words, this study allows us to unveil under which conditions a country offers a high/low score of value added in services. Theories such as the resource-based view and institutionalisation theory are necessary but insufficient to explain the real life complexities of value added services and their production since - by and large they neglect macro-environmental conditions. Because of this, it is argued that they cannot go as far as considering alternative causal recipes and explain how to achieve outcome conditions (in our case, value added services). Since data on value added services and prosperity of all countries are calculated and issued on a national scale, simulating value added services based on the conditions of a country increases the functionality of data for making policies at the national and international business service level. Brodie and Gustafsson (2016) emphasised the connection between theoretical advances and managerial usefulness in developing theory in service research. More importantly, previous research has not investigated value added services at the macro (country) level through exploring the attributes of the ingredients within different causal models. This is striking given that the competitiveness of countries depends also on the extent of the service value-added enabled by such countries' economic and social conditions (Kogut 1985).

\section{Theoretical framework and configural model}

Previous studies investigated the value-added process from the entrepreneurial theory of the firm and the resource-based view perspectives (see, e.g., Barney 1991; Oliver 1997; Wirtz et al., 2015). Most of these studies focussed on organisational change, reforms and types of transformation (Rindova and Kotha 2001) as well as the resources of organisations, including human resources and intellectual capital (Liu and Leach 2001; Zeghal and Maaloul 2010). In

addition, some studies have investigated the switch from the production of substantial products to high value-added activities like knowledge management (Davies 2003) and 
services provision through the use of technology and the internet (Kuo et al., 2009; Lexhagen 2004). Specifically, investment in employee talent and skill development, research and development (R\&D), customer relations and the use of IT and social media, are seen the main source of value creation in the new economy (Ostrom et al., 2015).

As Gustafsson et al. $(2016,10)$ recently advocate, for developing service research "we need a more nuanced and multifaceted perspective of research"; the present study answer this calls by applying complexity theory in order to rectify the deficiency of the resourcebased and institutionalisation theories in explaining the complex antecedents of service value added. Complexity theory is deemed to be particularly suited to the present study because this theory enables us to predict high or low scores of value added in the service industry by considering multiple recipes, and the conditions of various antecedents/actions (presence/absence of positive/negative role) that could affect the prediction (Olya and Altinay 2016).

Complexity theory is concerned with the behaviours of complex systems. It focuses on system interrelationships instead of system elements and draws upon the concepts from various fields of natural sciences in order to explain how complex systems emerge through the self-organising efforts of their interacting elements (Holland 1995; Kauffman 1995; Marion 1999). These principles have inspired many academics and practitioners in the fields of business management and marketing and thus provided them with a useful explanatory framework to better understand the behaviour of both organisations and value added as complex systems (Mitleton-Kelly 2003; Woodside 2015). Complexity theory can help capture a nonlinear view of the business world and argues that organisations and value added systems - as complex adaptive systems - are composed of a large number of diverse individual agents constantly acting and reacting to what the other agents are doing (Waldrop 1992). Non-linearity governs interactions among agents and small causes of the interactions among the agents may create large, unanticipated effects (Stacey et al., 2000). Understanding 
such complexity can help organisations and value-added systems develop creative and adaptive strategies that can mitigate undesirable consequences (Olya and Altinay 2016).

Thanks to its virtues, complexity theory has provided a solid foundation for building and testing theory in services marketing (see Gummesson 2008; Woodside 2014; Wu et al., 2014). In this context, as eloquently explained by Woodside (2014), a single antecedent is rarely sufficient (even though it may be necessary) for predicting a high or low score in a desired outcome. This is the first tenet of complexity theory. This suggests that a complex combination of factors affects the desired outcome. This is the second tenet of complexity theory, also described as 'the recipe principle'. The third tenet of complexity theory is called 'the equifinality principle' (Woodside 2014), referring to the occurrence of multiple causal configurations that are sufficient in predicting an outcome (in other words, a multiplicity of paths can lead to the same outcome). The 'causal asymmetry principle' is the fourth tenet of complexity theory. According to this tenet causal recipes that are capable of predicting an outcome are unique, and not the mirror opposites of recipes of a different outcome and, because of this, causes of acceptance may not be informative as to the causes of failure. The fifth tenet refers to the potential positive or negative effect of an individual feature (attribute or action) in a causal configuration depending on the presence or absence of other factorial conditions in a recipe. The final tenet of complexity theory assumes that a few exceptions occur for high $\mathrm{X}$ scores for a given recipe that work well for predicting high $\mathrm{Y}$ scores (Woodside 2014).

We argue that a conventional research approach would not suffice to explain the complexity of the social phenomena of value added services at the macro level. We, therefore, consider the use of complexity theory as paramount to provide richer insights regarding the interaction and combination of causal antecedents in simulating a high or low score in desired value added service outcomes in the service industries. 
Given the above, we hypothesise that a simple antecedent (e.g., entrepreneurship) will not be sufficient for predicting a high score in value added of services (first tenet). Instead, a complex set of factors (e.g., economy, entrepreneurship and opportunity, governance, education, health, safety and security, personal freedom, and social capital) is consistently sufficient to explain the value added service in a country (second tenet: the recipe principle). Following the third tenet of complexity theory, in this empirical study, it is expected that multiple patterns (i.e., economy, entrepreneurship and opportunity, governance, education, health, safety and security, personal freedom, and social capital) are sufficient for predicting a high score in value added of services. We also assume that a causal recipe for predicting the value added of services is unique and not the mirror opposite of recipes of a different outcome (tenet four). As aforementioned, if a complex combination of "economy, entrepreneurship and opportunity, governance, education, health, safety and security, personal freedom, and social capital" is considered a causal recipe for a high score in service value added, not necessarily an established recipe of "negation of economy, entrepreneurship and opportunity, governance, education, health, safety and security, personal freedom, and social capital", is consistently sufficient for the prediction of a low score in service value added. Consistent with the fifth tenet, the study also proposes that a causal configuration could result in different service value added outcomes depending on the presence or absence of other factorial conditions (economy, entrepreneurship and opportunity, governance, education, health, safety and security, personal freedom, and social capital) in a causal recipe. Following the sixth tenet, this study also expects differences in terms of service value added in service industries.

Differing from conventional symmetric approaches, antecedent and outcome conditions are illustrated by means of a Venn diagram. This study used 8 rather than 7 simple conditions but showing all 8 in one Venn diagram is unwieldy and the model designed with 
seven set Venn diagram (Duşa 2007) is therefore illustrated. The proposed configural model depicted in Figure 1 was tested based on fsQCA in accordance with the major tenets of complexity theory. Arrow A1 represents causal recipes (i.e., models) for predicting a high score of value added of services, while arrow A2 shows causal models for simulating negation of value added of services as an alternative outcome condition.

\section{Figure 1 here}

\section{Methodology}

The thematic process followed for conducting the empirical analysis is illustrated in Figure 2. Since few empirical studies have used fsQCA as their analytical approach as well as complexity theory for modelling complex outcomes in the field of service marketing (Olya and Altinay 2016; Wu et al., 2014), the illustration of major phases of our methodological strategy should prove useful. As shown in Figure 2, eight indictors of prosperity are obtained from the Legatum Institute (2016) and data of value added of services collected from the World Bank (2016). A pair set of eight antecedents and outcome conditions are matched providing data for the analysis of 104 countries over the period 2009-2014 (i.e. composite score of a six-year-long dataset). We conducted correlation and multicollinearity analyses to identify the functionality of testing the proposed model based on fsQCA and complexity theory (for details regarding the justifications for priority of asymmetric modelling of complex socio-economic issues, see the pioneering research by Olya and Altinay 2016).

\section{Figure 2 here}

The asymmetric modelling of the proposed configural model was done using fsQCA software (see Ragin 2008). The fsQCA consists of three steps: calibration (transformation of number value to fuzzy-set value); generating a fuzzy truth table; and counterfactual analysis. The Quine-McCluskey technique (based on minimising Boolean functions) was applied to simplify the fuzzy truth table algorithm that identifies causal models for predicting value 
added. These analytical processes were undertaken for modelling both high and low scores of value added of services (see arrows A1 and A2 in Figure 2). The fuzzy XY plot was sketched to show asymmetric association of the causal model with outcome conditions. This plot also demonstrates the cases that have a high degree of membership in predicting value added when their conditions are in line with the proposed causal recipe.

Predictive validity of the model ensures the predictive ability of configural model with a separate sample. This study divided the dataset into two subsamples (i.e. subsample1 with 52 cases and subsample 2 with 52 countries). The results of fsQCA explored using subsample 1 are tested with data from subsample 2. A high level of coverage and consistency, of the model of subsample 1 tested with data from subsample 2, provides evidence of predictive validity of the proposed configural model (for an analogous testing procedure, see $\mathrm{Wu}$ et al., 2014). Following the state-of-the-art approach employed by Woodside (2014), the results of fsQCA were assessed based on major tenets of complexity theory to determine whether the proposed configural model is theoretically matched with asymmetrical thinking.

\section{Results and discussion}

\subsection{Model testing results}

Results of correlation analyses are presented in Table I, appendix A. According to the results, study variables are highly correlated. There is evidence of multicollinearity when eight antecedents are regressed on the dependent variable (i.e., value added service). For example, the Variance Inflation Factor (VIF) for entrepreneurship and opportunity is 16.95, and 9.92 for health, which indicates that multicollinearity is an issue in symmetrical modelling of value added service (O'brien 2007). The fsQCA tackles the issue of multicollinearity by estimating a combined configuration, not the net effect of a single factor ceteris paribus, as a causal recipe for predicting an outcome condition (Anckar 2008; Olya and Altinay 2016; 
Ragin 2008; Woodside 2013; Wu et al., 2014). It is well known that the presence of multicollinearity can affect the reliability of the results in symmetrical methods (e.g., regression analysis). But we wish to reiterate that this is not so in the case of fsQCA, which - unlike regression analysis - does not require the absence of multicollinearity. fsQCA is robust to multicollinearity issues in our application because the analysis estimates a combination of eight indicators considered jointly as a causal model, not the net effect of each factor independent of the others.

Results of exploring causal conditions for simulating high and low scores using fsQCA are provided in Table 1. 'Coverage' 'and consistency' are two criteria for supporting the causal recipe (the specific combination of causally relevant ingredients) as a consistent and sufficient model for predicting outcome conditions. Consistency and coverage in the asymmetrical approach are analogous to correlation and the coefficient of determination $\left(\mathrm{R}^{2}\right)$ measure in conventional statistical analysis, respectively. The numerical examples for calculating consistency $\quad\left(\left(X_{i} \leq Y_{i}\right)=\sum\{\min (X i, Y i)\} / \Sigma(X i)\right) \quad$ and $\quad$ coverage $\left.\left(X_{i} \leq Y_{i}\right)=\Sigma\{\min (X i, Y i)\} / \Sigma(Y i)\right)$ are provided in Ragin's (2008) guidelines, where $\mathrm{Xi}$ is case i's membership score in set $\mathrm{X}$, and Yi is case i's membership score in the outcome condition. According to the fsQCA results, three causal recipes (A1: M1-M3) indicate a high score of value added service. The coverage $(=0.524)$ and consistency $(=0.854)$ values exceed and hence satisfy the threshold values ( $>0.2$ and $>0.8$, respectively) proposed by Ragin (2008). Model 1 reveals that a high level of value added in service industry is obtained in conditions where economy, entrepreneurship and opportunity, governance, health, personal freedom, and social capital are all at a satisfactory level (coverage $=0.387$, consistency $=$ 0.845). Since fsQCA functions are based on Boolen algebra, * and $\sim$ represent "and" and "negation" (i.e., low level of condition), and these are considered in the interpretation of the fsQCA results. For example, Model 2 explains that strong conditions in economy, education 
and social capital lead to a high score of value added service, even if conditions in entrepreneurship and opportunity, governance, health, safety and security, and personal freedom are not satisfactory (coverage $=0.052$, consistency $=0.851)$. This means that a high score of value added may not necessarily be achieved by having high scores in all eight subindices of prosperity. In other words, we should not necessarily expect nor seek high levels of value added in prosperous countries only. For example, conditions in Argentina are similar to the causal recipe of Model 2. Model 3 describes strong economy, education, health, safety and security, social capital, and a low level of entrepreneurship and opportunity governance, and personal freedom as consistent and sufficient causal conditions for achieving a high score of value added service. Thailand offers an exemplar of a case in which conditions overlap (matched) with the configuration of Model 3.

\section{Table 1 here}

The asymmetric relationship of the causal model (e.g., M1) with outcome condition ('advase') is depicted, as the XY plot, at the bottom of Table 1. The relationship does not appear to follow an asymmetric pattern. The plot shows a different level of membership of cases (i.e., countries) in predicting value added service in which the causal conditions match with the recipe of M1. For example, cases 3 (Norway), 9 (Australia), 29 (Finland) and 22 (Denmark), demonstrate high levels of membership within Model 1, that result in a high score of value added service (see XY plot in Table 1). These results are in accordance with the findings of Imberman and Lovenheim (2016), who conclude that value added service varies by location.

To predict a low score of value added service (A2: advase), one causal model was explored which explains poor economy, entrepreneurship and opportunity, governance, education, health, safety and security, social capital and good level of personal freedom. Conditions in Senegal $(0.77 ; 0.98)$, Nicaragua $(0.68 ; 0.98)$, Bangladesh $(0.63 ; 0.56)$, Dominican $(0.6 ; 0.90)$, and Ecuador $(0.53 ; 0.86)$ are in line with model 1 that describes a 
sufficient and consistent situation leading to a low score of value-added service (A2: M1 in Table 1). Such results are similar to the findings of Elango and Wieland (2015) and Huber and Danino (2012) that indicated the capturing the additional value becomes more important and more fragmented based on country conditions.

\subsection{Predictive validity}

The results of predictive validity are presented in Table 2 . The fsQCA results from subsample 1 give us a coverage value of 0.525 , and a Consistency value of 0.834 . The XY plot of this causal model is sketched (XY plot A1). To provide evidence of predictive validity, Model 1 is tested with data from subsample 2, and acceptable values for coverage and consistency are reported (XY plot A2). The asymmetric pattern of XY plots A1 and 2 is similar to the relationship of Model 1 in the original dataset (XY plot in Table 1). These results show that the proposed configural model has predictive ability of the causal recipes (Wu et al., 2014). As Ordanini et al. (2013) argued, the recipe for predicting service innovation is more important than its ingredients, checking the predictive validity of the recipe with another dataset for generalisation of the fsQCA results is, therefore, imperative. Specifically, the present study used a set of socio-economic factors of countries to predict value added in services. Since the factors are dynamic and their interactions are also complex causal recipes that meet the criteria of predictive validity, we can use a reliable action plan for targeting countries with high value added in services and discard the countries which offer low value added. This approach satisfactorily addresses Brodie and Gustafsson's (2016, 3) concern about "the disconnection between theoretical advances and managerial usefulness".

\section{Table 2 here}

\subsection{Complexity Theory evaluation}

The fsQCA results were evaluated on the basis of the key tenets of complexity theory (Woodside 2014). However, the recipe of Model 1 (A1) suggests that valuable resources and 
conditions lead to a high level of success/achievement - in this case, a high score of value added service. These results are in line with the precepts of resource-based theory. Nevertheless, this theory is insufficient to justify other causal conditions (M2 and M3) which represent a poor situation in entrepreneurship and opportunity, governance, and personal freedom, along with conditions of other antecedents, while describing recipes for achieving a high score of value added service (Table 1). Considering the asymmetric relationship of the causal model and outcome condition (i.e., value added service), the proposed configural model is supported by tenets of complexity theory.

Table 1 shows that a simple antecedent (e.g., economy) is necessary but insufficient for predicting high scores of value added service. Therefore, Tenet 1 is supported. The fsQCA results provide evidence in support of Tenet 2, named as the 'recipe principle', because three consistent and sufficient causal models describe a high score of value added service and one causal recipe predicts negation of value added service (Table 1). Tenet 3 (i.e., the equifinality principle) represents a unique complex antecedent configuration (e.g., Model 1) that is sufficient but not necessary for predicting a high score of value added service. According to the fsQCA results, there are two other (M2 and M3) sufficient alternative paths (or algorithms) that are able to predict high scores of value added service (see A1 in Table 1).

Comparing A1 and A2, causal configurations predicting a high score of value added service are not simply mirror opposites of the causal recipe simulating a low level of value added service. This is evidence of causal asymmetry, thus providing empirical content to Tenet 4. We consider this result as very important for marketers and decision makers who may be interested not only in evaluating whether/how the conditions match the algorithms for a high score of value added service but also in whether/how the causal conditions lead to a low level of value added service. The attributes of each simple antecedent depend on 'action' of other ingredients in causal recipes. For example, in Models 1 and 3, 'safety and security' positively contributes to achieving a high score of value added service while it has a negative 
impact in Model 2, a result that can be explained by considering attributes of other indicators in the algorithm. Hence, Tenet 5 is also supported.

As the XY plot reported in Table 1 illustrates, the causal complex configuration in Model 1 is matched with conditions in some cases (countries) though there are other countries which, while displaying conditions inconsistent with the recipe of Model 1, nevertheless provide a high score of value added service. Accordingly, the magnitude of coverage is less than 1.00 (Table 1). Therefore, Tenet 6 is supported. These findings reveal that complexity theory supports the results of the proposed configural model tested using fsQCA. As Wu et al. (2014), Olya and Altinay (2016), and Hsiao et al. (2015) found, complexity theory provides a deeper insight into simulating social complex outcomes (i.e., value added) in the service industry, in response to a call by Mitchell (2015) for further research in the field.

\section{Conclusion}

This exploratory study extends our knowledge about antecedents of value added in service industries at the national level. The results address two key questions: (i) whether prosperity sub-indices are able to inform the development of a consistent and sufficient model for predicting value added at a macro level (theoretical contribution); and (ii) how the causal antecedents must be combined to simulate high or low levels of value added (methodological contribution). The fsQCA and complexity theory, as a practical approach for crafting and testing the model, offers a roadmap representing the casual conditions for obtaining high and low scores of value added.

This study explored causal complex models for predicting value added in service industries using eight indictors of prosperity. A proposed configural model was developed and then tested using fsQCA with data drawn from 104 countries from 2009 to 2014. The evaluation of fsQCA results with six main tenets of complexity theory reveals that the 
proposed configural model is well explained by this theory. The nonlinear, dynamic and complex interactions of socio-economic issues can be modelled by fsQCA and complexity theory, which is a relatively new analytical approach for analysing such phenomena based on asymmetric thinking.

The results of fsQCA indicate that a high level of value added is achieved in service industries of prosperous countries such as Norway and Australia (see A1: Model 1 in Table 1). This recipe, however, is not the only causal recipe that predicts a high score of valueadded service (see A1: Models 2 and 3 in Table 1). There are some countries (e.g., Argentina and Thailand) in which entrepreneurship and opportunity, governance, and personal freedom conditions are not at the level of prosperous countries but irrespective of this, a high level of value added in the service industries is achieved. These results confirm that the attribute of antecedents in predicting value added service depends on the action (presence or absence and positive or negative role) of other ingredients in the causal recipes. These complex interactions cannot be justified by symmetrical approaches.

This study calculated an algorithm for simulating a causal configuration leading to a low score of value added in service industries (A2: Model 1 in Table 1). Senegal's condition is in accordance with the causal configuration of Model 1 in A2. Policy makers, marketers, and investors are able to monitor the conditions of a country based on the instruction provided (see the causal models of A1 and A2 in Table 1). This monitoring can allow direct investment in services with a high level of value added, and reduced business activity in service industries of a country in which causal conditions lead to a low score of value added.

This study explored causal complexity of value added service using a large dataset of 104 countries over a six-year period that not only allows for a worldwide (universal) analysis but also mitigates temporal fluctuations of eight causal indicators and value added, our outcome condition. Evidence of predictive ability of the proposed configural model using a distinct dataset is also provided. The study offers a profitable pathway for further research 
intending to employ sub-indices of prosperity to capture the macro socio-economic conditions of a country in the modelling of value added in the service industry as well as other sectors. However, although the prosperity index provides a comprehensive overview of the socio-economic conditions of a country, future studies could explore other possible predictors of value added in the service industries, thereby extending our analysis. The process of application of fsQCA and complexity theory also provides a valuable blueprint for solving other complex outcome conditions in the service-marketing nexus.

Important policy and managerial implications flow from our findings. Policy makers need to take a holistic approach in identifying and supporting the antecedents of value added services. None of the factors can be considered in isolation or independently. Instead, value added services can be stimulated by taking economic measures, investing in entrepreneurship and opportunity identification and, improving governance and education, health, safety and security, personal freedom and social capital holistically and simultaneously. Marketing managers cannot think of their organisations in isolation from these macro antecedents as they monitor changing dynamic customer needs and wants, and position themselves in relation to competitors' offerings. Improving value added services requires gathering and understanding market intelligence with regards to economic indicators, entrepreneurship opportunities, governance structures, education systems, health, safety and security measures, personal freedom and social capital, holistically. Our findings can help managers adapt their strategy so as to target countries with a high score of value added service and avoid targeting countries whose conditions (following the causal model) lead to a low score of added value.

\section{Notes}

1. Also included are imputed bank service charges, import duties, and any statistical discrepancies noted by national compilers, as well as discrepancies arising from rescaling (World Bank 2016). 
Appendix A. Table I here 


\section{References}

Ahmet Erkoyuncu, J., Roy, R., Shehab, E., \& Kutsch, E. (2014), “An innovative uncertainty management framework to support contracting for product-service availability. Journal of Service Management, 25(5), 603-638.

Anckar, C. (2008), "On the applicability of the most similar systems design and the most different systems design in comparative research", International Journal of Social Research Methodology, 11(5), 389-401.

Armstrong, J. S. (2011), "Illusions in regression analysis", International Journal of Forecasting, 28, 689-694.

Barney, J. (1991), "Firm resources and sustained competitive advantage. Journal of management, 17(1), 99-120.

Brodie, R. J., \& Gustafsson, A. (2016), "Enhancing theory development in service research", Journal of Service Management, 27(1), 2-8.

Burch, D., Lawrence, G., Green, G. P., Ichijo, K., Nonaka, I., Pimentel, M., ... \& Carneiro, M. J. (2007), “World Development Report 2008: agriculture for development (No. E14 231)", The World Bank.

Chandra, P., Chu, Y. H., Fisher, A., Gao, J., Kosak, C., Ng, T. E., ... \& Zhang, H. (2001), "Darwin: Customizable resource management for value-added network services", IEEE Network, 15(1), 22-35.

Corley, K. G., \& Gioia, D. A. (2011). Building theory about theory building: what constitutes a theoretical contribution?. Academy of management review, 36(1), 12-32.

Cunha, J. M., \& Miller, T. (2014), "Measuring value-added in higher education: Possibilities and limitations in the use of administrative data", Economics of Education Review, 42, 64-77.

Daim, T. U., Basoglu, N., Kargin, B., \& Phan, K. (2014), "Service innovation adoption: The case of value-added mobile services", Journal of the Knowledge Economy, 5(4), 784-802.

Davies, A.C. (2003), "Adding Value to Systems Integration", The Business of System Integration, Oxford University Press, Oxford.

Duşa, A. (2007), "User manual for the QCA (GUI) package in R", Journal of Business Research, 60(5), 576-586.

Echchakoui, S. (2016), "Relationship between sales force reputation and customer behavior: Role of experiential value added by sales force", Journal of Retailing and Consumer Services, 28, 54-66.

Edvardsson, B., Tronvoll, B., \& Gruber, T. (2011), "Expanding understanding of service exchange and value co-creation: a social construction approach", Journal of the Academy of Marketing Science, 39(2), 327-339.

Gigerenzer, G., \& Brighton, H. (2009), "Homo heuristicus: Why biased minds make better inferences", Topics in Cognitive Science, 1(1), 107-143. 
Grönroos, C. (1997), "Value-driven relational marketing: from products to resources and competencies", Journal of marketing management, 13(5), 407-419.

Gustafsson, A., Högström, C., Radnor, Z., Friman, M., Heinonen, K., Jaakkola, E., \& Mele, C. (2016), "Developing service research-paving the way to transdisciplinary research”, Journal of Service Management, 27(1), 9-20.

Gustafsson, A., Aksoy, L., Brady, M. K., McColl-Kennedy, J. R., Sirianni, N. J., Witell, L., \& Wuenderlich, N. V. (2015), "Conducting service research that matters", Journal of Services Marketing, 29(6/7), 425-429.

Hilton, T., Hughes, T., \& Chalcraft, D. (2012), "Service co-creation and value realisation”, Journal of Marketing Management, 28(13-14), 1504-1519.

Holland, J. H. (1995), Hidden order: How adaptation builds complexity. Cambridge, MA: Perseus Books.

Hsiao, J. P. H., Jaw, C., Huan, T. C., \& Woodside, A. G. (2015), “Applying complexity theory to solve hospitality contrarian case conundrums: Illuminating happy-low and unhappyhigh performing frontline service employees", International Journal of Contemporary Hospitality Management, 27(4), 608-647.

Huber, B. and Danino, S. (2012), Global Business Services: Taking Business Support Functions to the Next Level, Information Services Group, Stamford, CT.

Imberman, S. A., \& Lovenheim, M. F. (2016), "Does the market value value-added? Evidence from housing prices after a public release of school and teacher valueadded", Journal of Urban Economics, 91, 104-121.

Jiao, J., Ma, Q., \& Tseng, M. M. (2003), “Towards high value-added products and services: mass customization and beyond", Technovation, 23(10), 809-821.

Kan, A. K. S., Adegbite, E., El Omari, S., \& Abdellatif, M. (2016). On the use of qualitative comparative analysis in management. Journal of Business Research, 69(4), 1458-1463.

Kauffman, S. A. (1995), At home in the universe: the search for laws of selforganization and complexity. Oxford: Oxford University Press.

Kogut, B. (1985), "Designing global strategies: Comparative and competitive value-added chains", Sloan management review, 26(4), 15-28.

Kuo, Y. F., Wu, C. M., \& Deng, W. J. (2009), “The relationships among service quality, perceived value, customer satisfaction, and post-purchase intention in mobile value-added services", Computers in human behavior, 25 (4), 887-896.

Legatum Institute (2016), The Legatum Prosperity Index, Retrieved February 07, 2016, from The Legatum Institute Foundation Web http://media.prosperity.com/2015/xls/2015_Variables.xlsx .

Legatum (2013), The Methodology and Technical Appendix. Retrieved April 7, 2016, from The Legatum Institute Foundation Web http://media.prosperity.com/2013/pdf/publications/methodology_2013_finalweb.pdf. 
Lexhagen, M. (2004), "The importance of value-added services to support the customer search and purchase process on travel websites", Information Technology \& Tourism, 7(2), 119-135.

Liu, A. H., \& Leach, M. P. (2001), "Developing loyal customers with a value-adding sales force: Examining customer satisfaction and the perceived credibility of consultative salespeople", Journal of Personal Selling \& Sales Management, 21(2), 147-156.

Madonia, G., Cracolici, M. F., \& Cuffaro, M. (2013), "Exploring wider well-being in the EU15 countries: An empirical application of the Stiglitz report", Social indicators research, 111(1), 117-140.

Marion, R. (1999), The Edge of Organization: Chaos and Complexity Theories of Formal Social Systems. New York: Corwin Press.

Martínez-Torres, M. R., Díaz-Fernández, M. D. C., Toral, S. L., \& Barrero, F. J. (2013), "Identification of new added value services on intelligent transportation systems", Behaviour \& Information Technology, 32(3), 307-320.

Meyer, R. H. (1997), "Value-added indicators of school performance: A primer", Economics of Education Review, 16(3), 283-301.

Mitchell, V. W. (2015), “30 years of perceived risk: Some research issues", In Proceedings of the 1994 Academy of Marketing Science (AMS) Annual Conference (pp. 350-355), Springer International Publishing.

Mitleton-Kelly, E. (2003), "Ten principles of complexity and enabling infrastructures", Complex systems and evolutionary perspectives on organisations: The application of complexity theory to organisations, 23-50.

O’brien, R. M. (2007), “A caution regarding rules of thumb for variance inflation factors", Quality \& Quantity, 41(5), 673-690.

Oliver, C. (1997), "Sustainable competitive advantage: Combining institutional and resourcebased views", Strategic management journal, 18(9), 697-713.

Olya, H. G., \& Altinay, L. (2016), "Asymmetric modeling of intention to purchase tourism weather insurance and loyalty", Journal of Business Research, 69(8), 2791-2800.

Olya, H. G., \& Mehran, J. (2017), "Modelling tourism expenditure using complexity theory", Journal of Business Research, 75, 147-158.

Ordanini, A., Parasuraman, A., \& Rubera, G. (2013), "When the recipe is more important than the ingredients a qualitative comparative analysis (QCA) of service innovation configurations", Journal of Service Research, 1-16. Doi: 1094670513513337.

Ostrom, A. L., Parasuraman, A., Bowen, D. E., Patricio, L., Voss, C. A., \& Lemon, K. (2015), "Service research priorities in a rapidly changing context", Journal of Service Research, 18(2), 127-159.

Ostrom, A. L., Bitner, M. J., Brown, S. W., Burkhard, K. A., Goul, M., Smith-Daniels, V., ... \& Rabinovich, E. (2010), "Moving forward and making a difference: research priorities for the science of service", Journal of Service Research. 13 (1), 4-36. 
Oswald, A. J. (2010), "Emotional prosperity and the Stiglitz Commission", British Journal of Industrial Relations, 48(4), 651-669.

Ragin, C. (2008), Redesigning Social Inquiry. Chicago, IL: University of Chicago Press.

Randers, J. (2012), "Greenhouse gas emissions per unit of value added (GEVA) - A corporate guide to voluntary climate action", Energy policy, 48, 46-55.

Rindova, V. P., \& Kotha, S. (2001), "Continuous "morphing”: Competing through dynamic capabilities, form, and function”, Academy of Management Journal, 44(6), 1263-1280.

Ryan, N. (1996), “Technology strategy and corporate planning in Australian high-valueadded manufacturing firms", Technovation, 16(4), 195-214.

Stacey, R.D., Griffin, D, and Shaw, P. (2000), Complexity and Management: Fad or Radical Challenge to Systems Thinking? London: Routledge.

Van Vliet, H. (2014), The Added Value of Business Models. CREATE-IT Applied Research Group Crossmedia. Retrieved on 07. February 2016, from http://www.static.hva.n1/binaries/content/assets/subsites/kc-dmci-create- it/assets_1/theadded-value-of-business-models.pdf.

Waldrop, M. (1992), Complexity: The Emerging Science at the Edge of Order and Chaos. New York: Simon \& Schuster.

Wirtz, J., Tuzovic, S., \& Ehret, M. (2015), "Global business services: Increasing specialization and integration of the world economy as drivers of economic growth", Journal of Service Management, 26(4), 565-587.

Woodside, A. G. (2013), "Moving beyond multiple regression analysis to algorithms: Calling for adoption of a paradigm shift from symmetric to asymmetric thinking in data analysis and crafting theory", Journal of Business Research, 66(4), 463-472.

Woodside, A. G. (2014), "Embrace• perform• model: Complexity theory, contrarian case analysis, and multiple realities", Journal of Business Research, 67(12), 2495-2503.

Woodside, A. G. (2015), "Iconic studies relevant for research in marketing and the Journal of Global Scholars of Marketing Science", Journal of Global Scholars of Marketing Science, 25(3), 259-278.

World Bank (2016), Services, etc., Value Added (current US\$), Retrieved February 07, 2016, from http://data.worldbank.org/indicator/NV.SRV.TETC.CD.

Wu, P. L., Yeh, S. S., Huan, T.C., \& Woodside, A. G. (2014), “Applying complexity theory to deepen service dominant logic: Configural analysis of customer experience-and-outcome assessments of professional services for personal transformations", Journal of Business Research, 67(8), 1647-1670.

Yihsing Yang, P., Luo, L. M., Li, C. S. J., Yang, Y. C., \& Lee, S. H. (2013), "The rise of the manufacturing service industry: the perspective of value-added chain model", Chinese Management Studies, 7(3), 403-418. 
Youngdahl, W. E., \& Loomba, A. P. (2000), "Service-driven global supply chains", International Journal of Service Industry Management, 11(4), 329-347.

Zéghal, D., \& Maaloul, A. (2010), "Analysing value added as an indicator of intellectual capital and its consequences on company performance", Journal of Intellectual capital, 11(1), 39-60.

\section{Appendix A.}

Table I. Correlation matrix and multicollinearity statistics

\begin{tabular}{lcccccccc}
\hline Indicators & 1 & 2 & 3 & 4 & 5 & 6 & 7 & 8 \\
\hline Economy & $(3.310)$ & & & & & & & \\
Entrepreneurship \& & $.806^{* *}$ & $(16.950)$ & & & & & & \\
$\quad$ opportunity & & & & & & & & \\
Governance & $.771^{* *}$ & $.898^{* *}$ & $(8.263)$ & & & & & \\
Education & $.697^{* *}$ & $.876^{* *}$ & $.711^{* *}$ & $(7.744)$ & & & & \\
Health & $.767^{* *}$ & $.899^{* *}$ & $.743^{* *}$ & $.921^{* *}$ & $(9.923)$ & & & \\
Safety & $.695^{* *}$ & $.879^{* *}$ & $.850^{* *}$ & $.793^{* *}$ & $.808^{* *}$ & $(5.826)$ & & \\
Personal freedom & $.565^{* *}$ & $.691^{* *}$ & $.768^{* *}$ & $.530^{* *}$ & $.543^{* *}$ & $.739^{* *}$ & $(3.044)$ & \\
Social capital & $.656^{* *}$ & $.757^{* *}$ & $.735^{* *}$ & $.623^{* *}$ & $.641^{* *}$ & $.683^{* *}$ & $.688^{* *}$ & $(2.741)$ \\
Value added Service & $.317^{* *}$ & $.300^{* *}$ & $.303^{* *}$ & $.252^{* *}$ & $.321^{* *}$ & $.179^{*}$ & $.210^{*}$ & $.283^{* *}$ \\
\hline Note: ${ }^{*}$ and ${ }^{* *}$ denote that the correlation is & statistically significant at the .05 and .01 levels, \\
respectively. Variance inflation factor appeared within the parenthesis. & & &
\end{tabular}




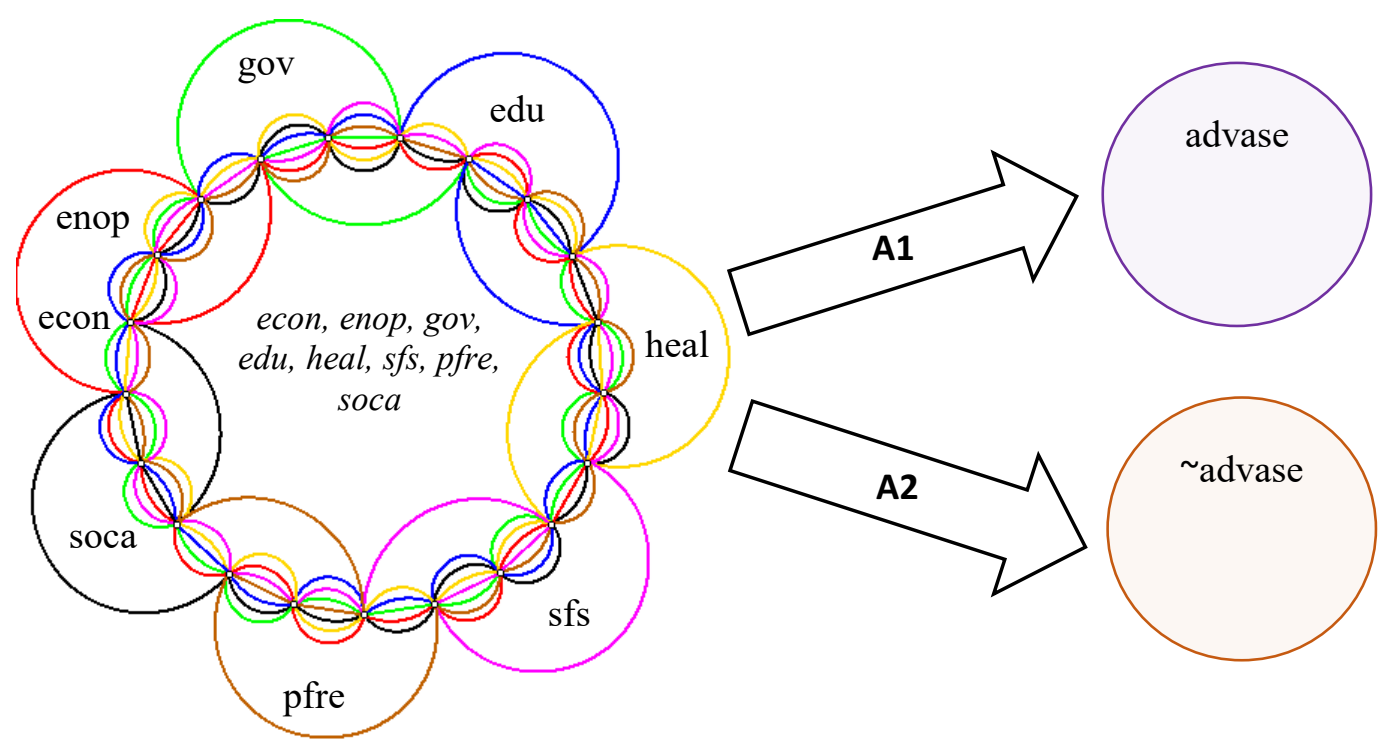

Note: econ: economy; enop: entrepreneurship \& opportunity; gov: governance; edu: education; heal: health; sfs: safety \& security; pfre: personal freedom; soca: social capital; is negation sign.

Figure 1. Complex configural model 


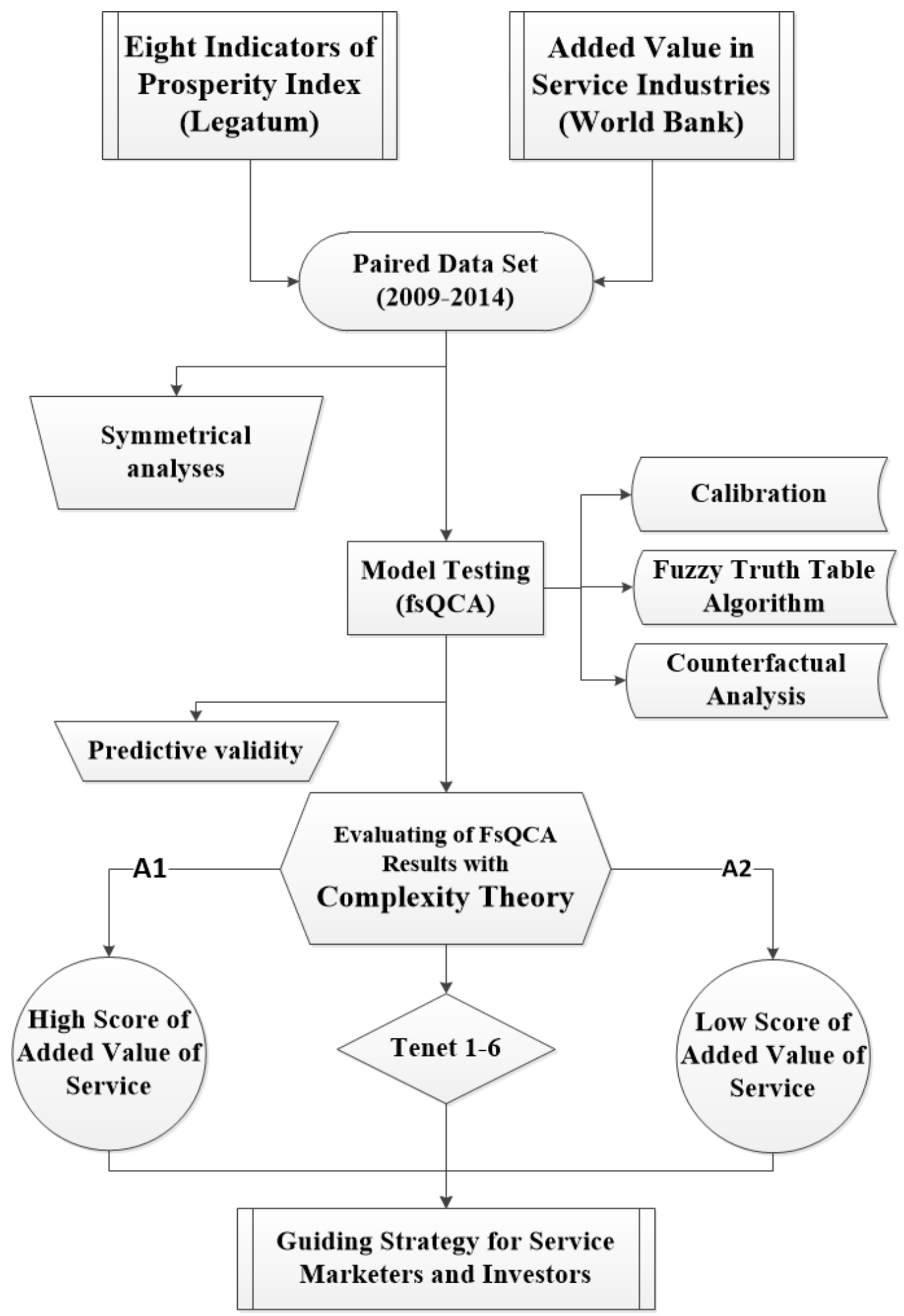

Figure 2. Research design 
Table 1. Causal recipes of value added and its negation with eight antecedents

\begin{tabular}{|c|c|c|c|}
\hline $\begin{array}{l}\text { Models for predicting high score of outcomes (A1) and the negation } \\
\text { of outcomes (A2) }\end{array}$ & $\begin{array}{l}\text { Raw } \\
\text { coverage }\end{array}$ & $\begin{array}{l}\text { Unique } \\
\text { coverage }\end{array}$ & Consistency \\
\hline \multicolumn{4}{|l|}{ A1: advase $=f($ econ, enop, gov, edu, heal, sfs, pfre, soca) } \\
\hline$--M 1$. econ*enop*gov*edu*heal*sfs*pfre*soca & 0.447 & 0.387 & 0.845 \\
\hline M2. econ* ${ }^{*} \sim$ enop $^{*} \sim$ gov $^{*}$ edu $* \sim$ heal $^{*} \sim$ sfs $^{*} \sim$ pfre $*$ soca & 0.126 & 0.052 & 0.851 \\
\hline M3. econ* enop* $*$ gov*edu*heal $*$ sfs $* \sim$ pfre* soca $^{*}$ & 0.085 & 0.001 & 0.823 \\
\hline \multicolumn{4}{|l|}{ Solution coverage: 0.524} \\
\hline \multicolumn{4}{|l|}{ Solution consistency: 0.854} \\
\hline A2: $\sim$ advase $=f($ econ, enop, gov, edu, heal, sfs, pfre, soca $)$ & $\begin{array}{l}\text { Raw } \\
\text { coverage }\end{array}$ & $\begin{array}{l}\text { Unique } \\
\text { coverage }\end{array}$ & Consistency \\
\hline 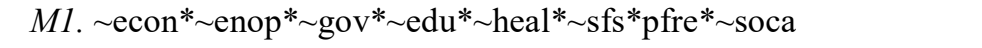 & 0.232 & 0.232 & 0.811 \\
\hline $\begin{array}{l}\text { Solution coverage: } 0.232 \\
\text { Solution consistency: } 0.811\end{array}$ & & & \\
\hline
\end{tabular}

A1: advase $=$ f(econ, enop, gov, edu, heal, sfs, pfre, soca)

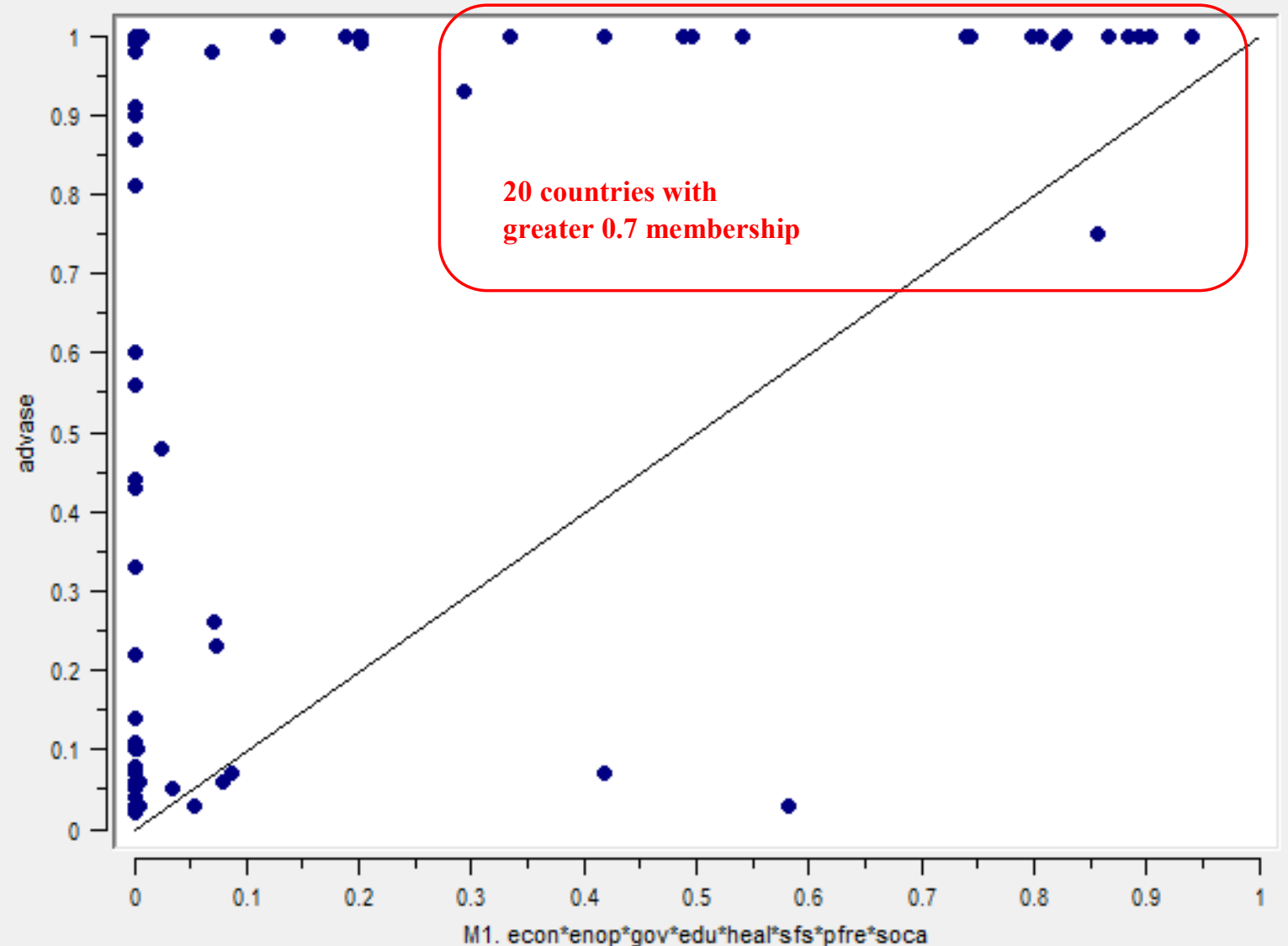

Note: econ: Economy; enop: Entrepreneurship \& Opportunity; gov: Governance; edu: Education; heal: Health; sfs: Safety \& Security; pfre: Personal Freedom; soca: Social Capital; advase: value added of service. Twenty cases with greater than 0.7 membership are Norway (coverage: 0.97, consistency: 1.00), Canada (0.96,1.00), Finland $(0.96,1.00)$, Australia $(0.95,1.00)$, Denmark $(0.95,1.00)$, Netherlands $(0.95,1.00)$, Sweden $(0.95,1.00)$, New Zealand $(0.93,0.75)$, Belgium $(0.92,1.00)$, Ireland (0.92,0.99), Austria (0.91,1.00), Germany (0.91,1.00), UK $(0.89,1.00)$, Switzerland $(0.87,1.00)$, Spain $(0.82,1.00)$, Slovenia $(0.76,0.07)$, France $(0.72,1.00)$, Poland $(0.71,1.00)$, Czech $(0.7,0.93)$, Japan $(0.69,1.00)$. 
Table 2. Results of predictive validity Models from subsample 1

Subsample 1: advase = f(econ, enop, gov, edu, heal, sfs, pfre, soca)

M1: econ*enop*gov*edu*heal*sfs*pfre*soca

0.487

0.431

0.823

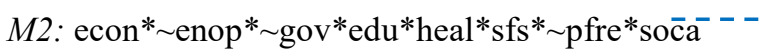

0.094

0.037

0.841

Solution coverage: 0.525

Solution consistency: 0.834

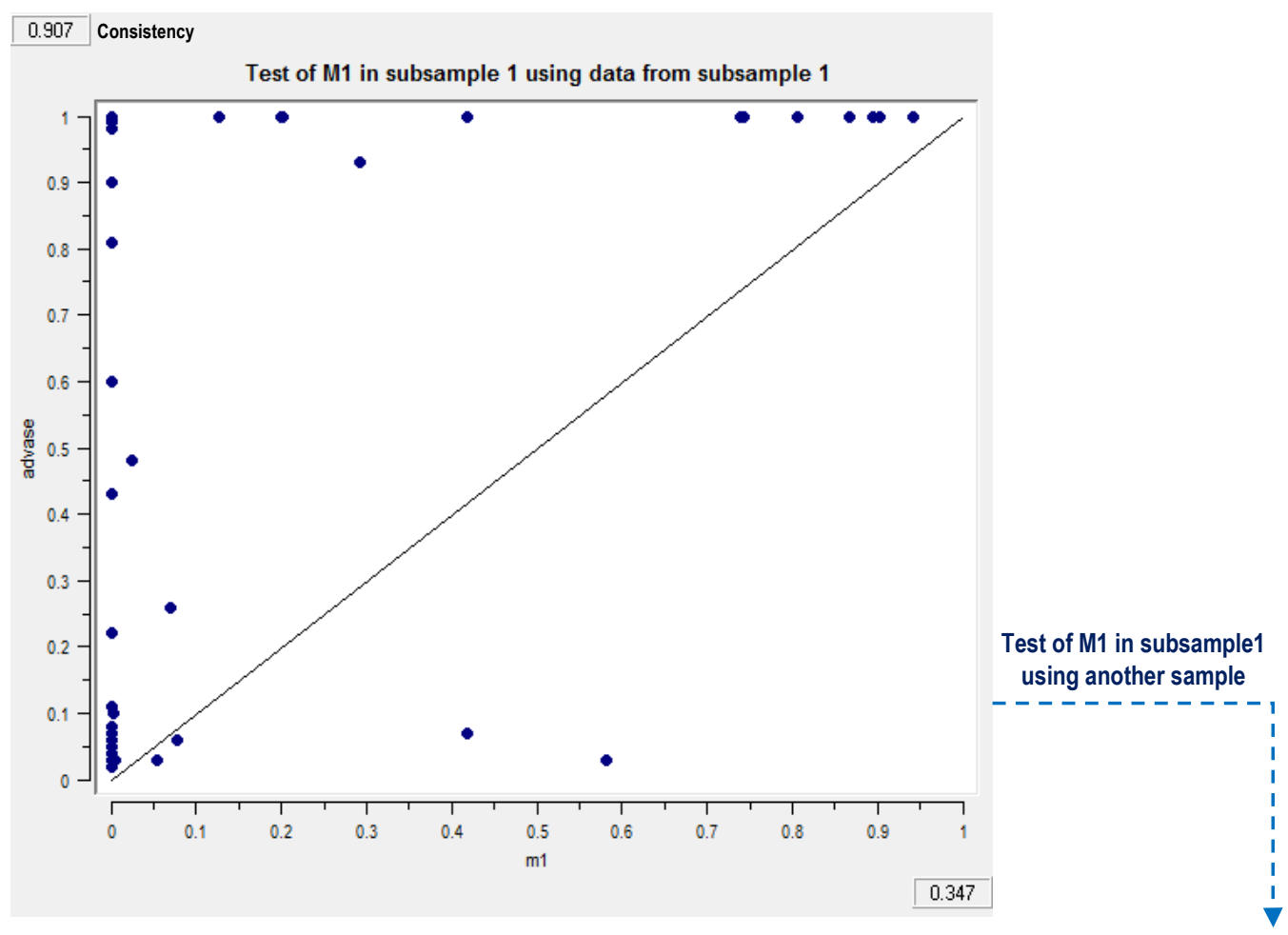




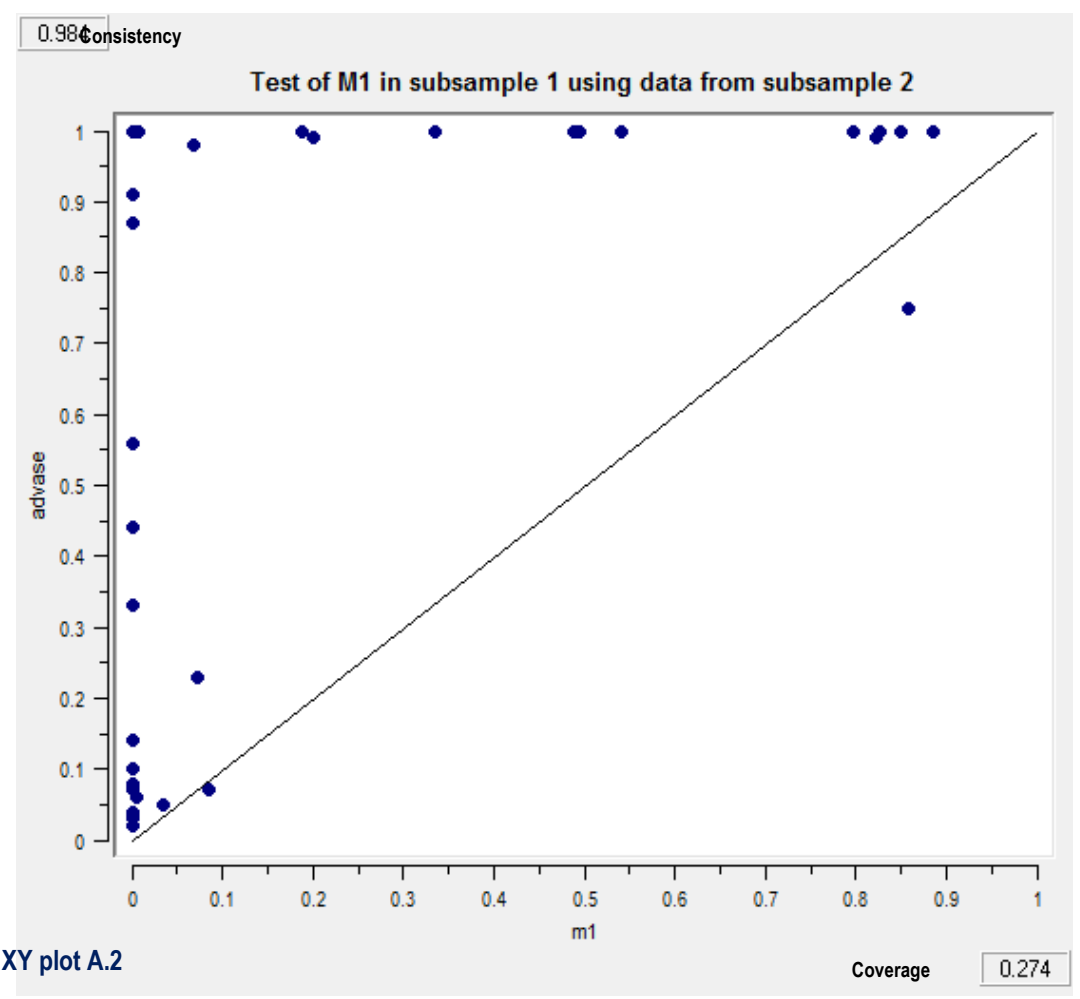

Note: $\mathrm{X}$ axis is causal model (M1) and $\mathrm{Y}$ axis is outcome (value added of service). 0: full non-membership, 1: full membership. 
